\title{
Inorganic-organic hybrid materials through post- synthesis modification: Impact of the treatment with azides on the mesopore structure
}

\author{
Miriam Keppeler ${ }^{1}$, Jürgen Holzbock ${ }^{1}$, Johanna Akbarzadeh², \\ Herwig Peterlik ${ }^{2}$ and Nicola Hüsing ${ }^{* 1,3}$
}

\section{Full Research Paper}

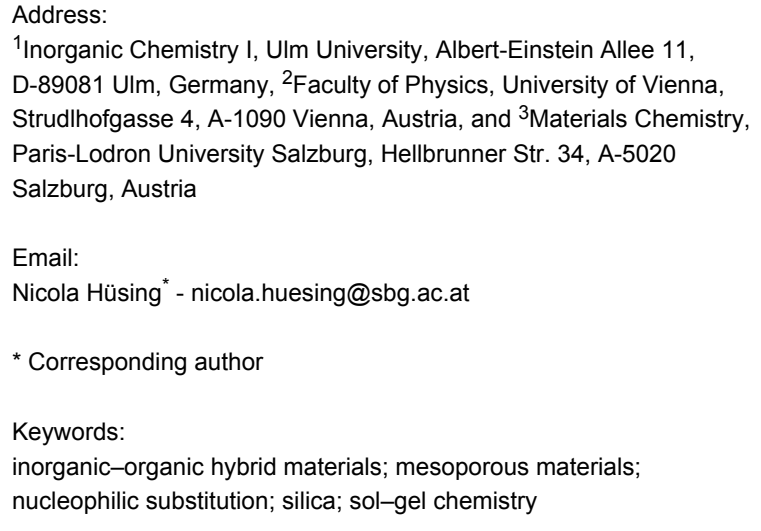

${ }^{1}$ Inorganic Chemistry I, Ulm University, Albert-Einstein Allee 11, D-89081 Ulm, Germany, ${ }^{2}$ Faculty of Physics, University of Vienna, Strudlhofgasse 4, A-1090 Vienna, Austria, and ${ }^{3}$ Materials Chemistry, Paris-Lodron University Salzburg, Hellbrunner Str. 34, A-5020 Salzburg, Austria

Email:

Nicola Hüsing ${ }^{*}$ - nicola.huesing@sbg.ac.at

* Corresponding author

Keywords:

inorganic-organic hybrid materials; mesoporous materials; nucleophilic substitution; silica; sol-gel chemistry

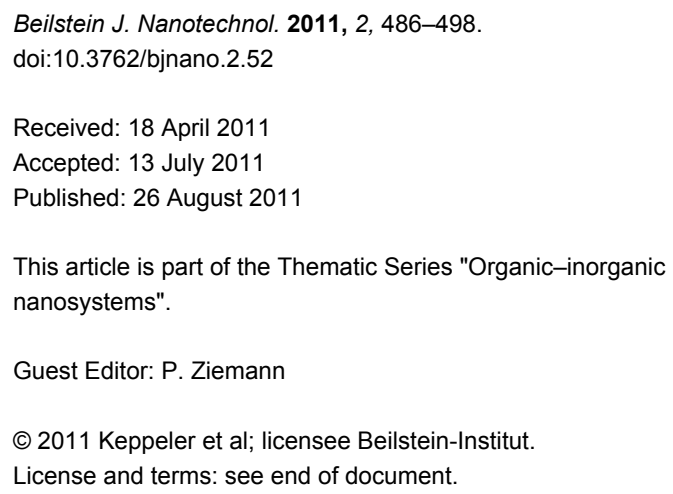

\begin{abstract}
Hybrid, hierarchically organized, monolithic silica gels, comprising periodically arranged mesopores and a cellular macroscopic network, have been prepared through a co-condensation reaction of tetrakis(2-hydroxyethyl)orthosilicate with chloromethyltrimethoxysilane or 3-(chloropropyl)-triethoxysilane. Subsequent conversion of the chloro groups into azido groups, by nucleophilic substitution with $\mathrm{NaN}_{3}$ in $N, N$-dimethylformamide, was conducted upon preservation of the monolithic structure. However, treatment with $\mathrm{NaN}_{3}$ had a strong influence on the structure in the mesoporous regime, with changes such as an increase of mesopore diameter, pore volume and lattice constants, as well as a concomitant decrease of the pore wall thickness, as confirmed by small angle X-ray scattering, transmission electron microscopy, and nitrogen sorption analysis. Similar effects were observed for unmodified silica gels by simple ageing in azide-containing media, whether a relatively small or a sterically demanding counter ion $\left(\mathrm{Na}^{+}\right.$or $\left.\left(\mathrm{H}_{3} \mathrm{C}\right)_{4} \mathrm{~N}^{+}\right)$was used. The structural modification did not seem to depend greatly on whether an organic aprotic solvent ( $N, N$-dimethylformamide, 1,1,3,3-tetramethylurea, 1,3-dimethyl-2-imidazolidinone) or a protic solvent that can form hydrogen bonds, such as water, was used.
\end{abstract}

\section{Introduction}

Inorganic-organic hybrid materials with tailored porosity on several length scales are of interest for a variety of applications, such as separation, adsorption, catalysis, energy storage, etc., due to the benefits arising from each pore size regime, e.g., rapid mass transport through macropores combined with selectivity provided by meso- or micropores. This is especially true 
for materials with uniform pore size distributions in the mesoporous (2-50 nm) and/or macroporous regime (>50 nm) [1-3].

A powerful tool in the preparation of stable, mesoscopically organized materials that are characterized by narrow mesopore size distributions, high specific surface areas and large pore volumes, is the application of cooperative self-assembly processes between supramolecular aggregates of organic molecules, oligomers or polymers and inorganic species such as alkoxysilanes for silica-based materials [4-12]. Since the first presentation by Kresge and Beck in 1992, these so-called M41S-materials have attracted great attention and their formation mechanism as well as the parameters influencing the textural properties have been well investigated [4,5]. It is wellknown that the manipulation of the dimensions and the state of aggregation of the supramolecular aggregates will directly influence the structural properties of the resulting inorganic porous material, and research efforts are devoted to the control of the structural properties through the synthesis conditions. For ordered mesoporous materials, whose syntheses are based on block copolymers such ethylene oxide $(\mathrm{EO})_{x}$-propylene oxide (PO) $)_{y}$-ethylene oxide $(\mathrm{EO})_{x}$, this can be achieved by variation of the length of the EO or PO blocks, by increasing the synthesis temperature or by the addition of inorganic salts $[6,9,13]$. Currently, progress in the synthesis protocols even allows for the preparation of different macroscopic morphologies such as powders, coatings, fibres, or monoliths.

Monoliths are of special interest for functional devices, e.g., as chromatography columns, or catalytic reactors. However, to allow mass transport with a minimal pressure build-up the presence of a macroporous network is indispensable. Such a second level of porosity in mesoporous silica monoliths can be introduced by several synthetic approaches: Dual templating with sacrificial templates, phase separation processes (e.g., based on polymers), or the application of diol/polyol-modified silanes [1-3,14-18].

Nakanishi and Lindén relied on polymerization-induced phase separation during sol-gel processing to form monolithic bodies with a hierarchical organisation of the pore structure at the meso- and macroscopic length scale [16,17]. The materials obtained were characterized by interconnected porosity on several length scales. The macropore diameter was controlled through PEO-siloxane interactions, whereas the mesopore diameter was governed by the presence of the surfactant, e.g., cetyltrimethylammonium bromide or a poly(ethylene oxide)based polymer. In our group, silicon diolates in the presence of surfactants were applied for the preparation of monolithic gels (silica and inorganic-organic hybrid networks) with a cellular network built up of macropores of about $2 \mu \mathrm{m}$ diameter and periodically arranged mesopores of $7 \mathrm{~nm}$ [18]. Each of these strategies allows for a high level of control over macropore/ mesopore size distribution, surface area, etc.

It is well known that ageing of silica gels in different environments or in hydrothermal conditions has a pronounced influence on the final gel structure $[19,20]$. Ageing at $100{ }^{\circ} \mathrm{C}$ in an autoclave yields mesoporous silica gels with larger pore sizes and pore volumes compared to gels aged in ethanol at room temperature due to promoted dissolution and reprecipitation processes [20]. Processes such as syneresis, Ostwald ripening, etc., are facilitated and accelerated with increasing temperature and pressure. The same is true for gels with periodically arranged mesopores or even mesostructured cellular foams [21].

Structural arrangements can be quite pronounced depending on the conditions of the post-treatment. One example is the so-called pseudomorphic transformation, in alkaline solutions and hydrothermal conditions, from amorphous mesoporous materials to well-organized mesoporous structures $[22,23]$.

Many silica gels are functionalized by organic groups specific for their eventual applications. Typical examples are the hydrophobization with methyl or phenyl groups, and even functional groups such as polymerizable moieties or metal-coordinating groups can be introduced [24]. These groups are typically incorporated either by post-synthetic grafting processes or by co-condensation reactions of different alkoxysilanes. The impact of these synthesis steps on the final pore structure is quite well investigated [25]. In post-synthetic functionalization procedures, a porous matrix with the desired pore size, pore connectivity, surface area, etc., is prepared prior to the modification step and the organic moieties are made to react with the surface silanol groups in a second step. For this approach, it is assumed that structural changes are minimal [25]. For the co-condensation approach, in which tetraalkoxysilanes $\left[\mathrm{Si}(\mathrm{OR})_{4}\right]$ are condensed to form an inorganic network in the presence of organically substituted tri-alkoxysilanes $\left[\mathrm{R}^{\prime}-\mathrm{Si}(\mathrm{OR})_{3}\right]$, network formation and thus structural features such as pore size, connectivity, etc., are strongly influenced by the presence of the organosilane [25].

These organo-functionalized silica gels can be further modified by chemical reactions with more complex functional groups; recent examples include $\mathrm{Cu}(\mathrm{I})$-catalyzed 1,3-dipolar cycloadditions, also termed Click reactions, on silica surfaces involving alkynes and azide functionalities [26-28]. Reviewing the literature on this topic reveals that most of the examples of postsynthesis surface chemical reactions are concerned with the successful chemical conversion, but the structure of the modified materials is in many cases not characterized in great detail. 
In a recent work, we have shown that prior to the Click reaction, the conversion from chloro to azido functionalities in silica monoliths is possible, but that this reaction concomitantly occurs with major structural changes [29].

The present work focuses on the influence of these surface functionalization reactions on the structural properties of preformed silica gels. The first section describes the nucleophilic substitution of hierarchically organized $\mathrm{SiO}_{2}-\left(\mathrm{CH}_{2}\right)_{1,3}-\mathrm{Cl}$ gels to give the corresponding $\mathrm{SiO}_{2}-\left(\mathrm{CH}_{2}\right)_{1,3}-\mathrm{N}_{3}$ gels in a saturated $\mathrm{NaN}_{3} / \mathrm{DMF}$ solution, with special focus on the structural changes of the silica backbone. In a second section the influence of different solvents and counter ions is discussed for unmodified hierarchically organized $\mathrm{SiO}_{2}$ gels as reference samples.

\section{Results and Discussion \\ Nucleophilic substitution of chloro- by azido groups on the silica surface}

Nucleophilic substitution of chloroalkyl-modified silica monoliths to azide-containing monoliths $\left(\mathrm{SiO}_{2}-\left(\mathrm{CH}_{2}\right)_{1,3}-\mathrm{Cl} \rightarrow\right.$ $\left.\mathrm{SiO}_{2}-\left(\mathrm{CH}_{2}\right)_{1,3}-\mathrm{N}_{3}\right)$ was conducted in a saturated solution of $\mathrm{NaN}_{3}$ in DMF on monolithic silica gels that had been treated with trimethylchlorosilane (Figure 1). During the course of this reaction, the macroscopic morphology of the monoliths was retained, and no significant influence on the macroporous network was observed. The gels had been treated with trimethylchlorosilane to remove reactive silanol groups and facilitate drying of the monoliths.

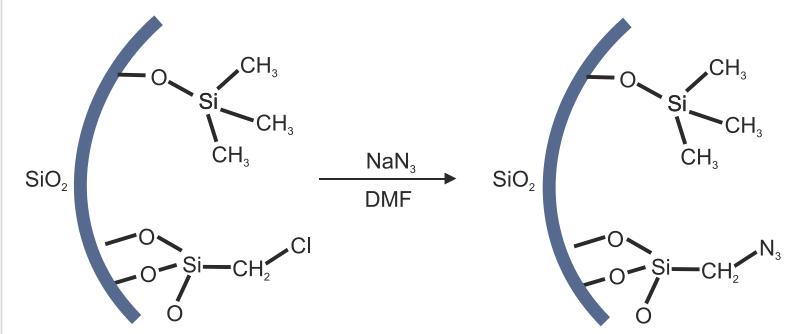

Figure 1: Schematic description of the nucleophilic substitution reaction for chloromethyl-modified silica pore surfaces.

Gels modified with chloromethyl groups (CMTMS) or chloropropyl groups (CPES) were subjected to the azide solutions. The number of azide groups per $\mathrm{nm}^{2}$ was evaluated according to a previously published method and was found to be in the range of $0.7 \mathrm{~nm}^{-2}$ (3.0 mmol CMTMS), $1.2 \mathrm{~nm}^{-2}$ (4.5 mmol CMTMS), $1.3 \mathrm{~nm}^{-2}$ (6.0 mmol CMTMS) and $0.7 \mathrm{~nm}^{-2}(3.0$ mmol CPES) at a reaction temperature of $60{ }^{\circ} \mathrm{C}$ [29]. The presence of the newly inserted azide functionalities was also confirmed by IR-ATR spectroscopy. This type of reaction has previously been reviewed for a variety of different silica surfaces, however, the influence of the reaction on the structural properties of the material has been mostly neglected [30].

This influence of the nucleophilic substitution on the porous structure of the meso/macroporous monoliths, with special emphasis on the long range hexagonal ordering of the mesopores, was evaluated by nitrogen sorption and small angle X-ray scattering (SAXS) analyses. Figure 2 shows the nitrogen adsorption/desorption isotherms at $77 \mathrm{~K}$ for modified silica gels before and after nucleophilic substitution $\left(\mathrm{SiO}_{2}-\left(\mathrm{CH}_{2}\right)_{1,3}-\mathrm{Cl} \rightarrow\right.$ $\left.\mathrm{SiO}_{2}-\left(\mathrm{CH}_{2}\right)_{1,3}-\mathrm{N}_{3}\right)$. The isotherms for the chloroalkylcontaining precursor materials are of type IV with $\mathrm{H} 2$ hysteresis loops according to the classification of Sing et al. [31], whereas the same samples after conversion of the chlorides into azides display hysteresis loops of $\mathrm{H} 1$ type indicating a narrow distribution of pores. In addition, the isotherms for $\mathrm{SiO}_{2}-\left(\mathrm{CH}_{2}\right)_{1,3}-\mathrm{N}_{3}$ exhibit stretching along the volume axis, adsorption and desorption isotherms display a sharper capillary condensation step and the relative pressure of the pore filling is shifted to larger values compared to the corresponding $\mathrm{SiO}_{2}-\left(\mathrm{CH}_{2}\right)_{1,3}-\mathrm{Cl}$. These variations in the hysteresis loops indicate an increase in the pore diameter and still a narrow pore size distribution for $\mathrm{SiO}_{2}-\left(\mathrm{CH}_{2}\right)_{1,3}-\mathrm{N}_{3}$.

The $\mathrm{H} 2$ type hysteresis loops obtained for $\mathrm{SiO}_{2}-\left(\mathrm{CH}_{2}\right)_{1,3}-\mathrm{Cl}$ suggest rather complex pore structures with interconnected pores of different size and shape, e.g., spherical mesopores interconnected by smaller windows or large pore channels with undulating walls are possible. The pore sizes calculated from the desorption branch of the isotherm, applying the Barrett-Joyner-Halenda (BJH) model, are in the range of $3.5-4.7 \mathrm{~nm}$ for all samples. However, for pore diameters smaller than $5 \mathrm{~nm}$ (in our case presumably given by the small interconnecting windows; see Table $1, D_{\mathrm{BJH}, \mathrm{Des}}$ ) the relative pressure at which desorption occurs is strongly influenced by fluid cavitations and instability of the meniscus [32]. In addition, the BJH model is based on the Kelvin equation, which describes the relationship between the relative vapour pressure in equilibrium and the radius of curvature of the meniscus [33]. Since a stable fluid meniscus with a given radius of curvature cannot be guaranteed for the desorption process in all systems, and the risk of obtaining physically meaningless results exists, the adsorption branch was also used to calculate the pore size distribution. This is not the case for the azido-functionalized samples $\left(\mathrm{SiO}_{2}-\left(\mathrm{CH}_{2}\right)_{1,3}-\mathrm{N}_{3}\right)$ with pore sizes larger than $5.4 \mathrm{~nm}$ for all samples. Here, the calculation using the desorption isotherm is favoured, since desorption processes are thermodynamically more stable compared to the corresponding adsorption processes. 

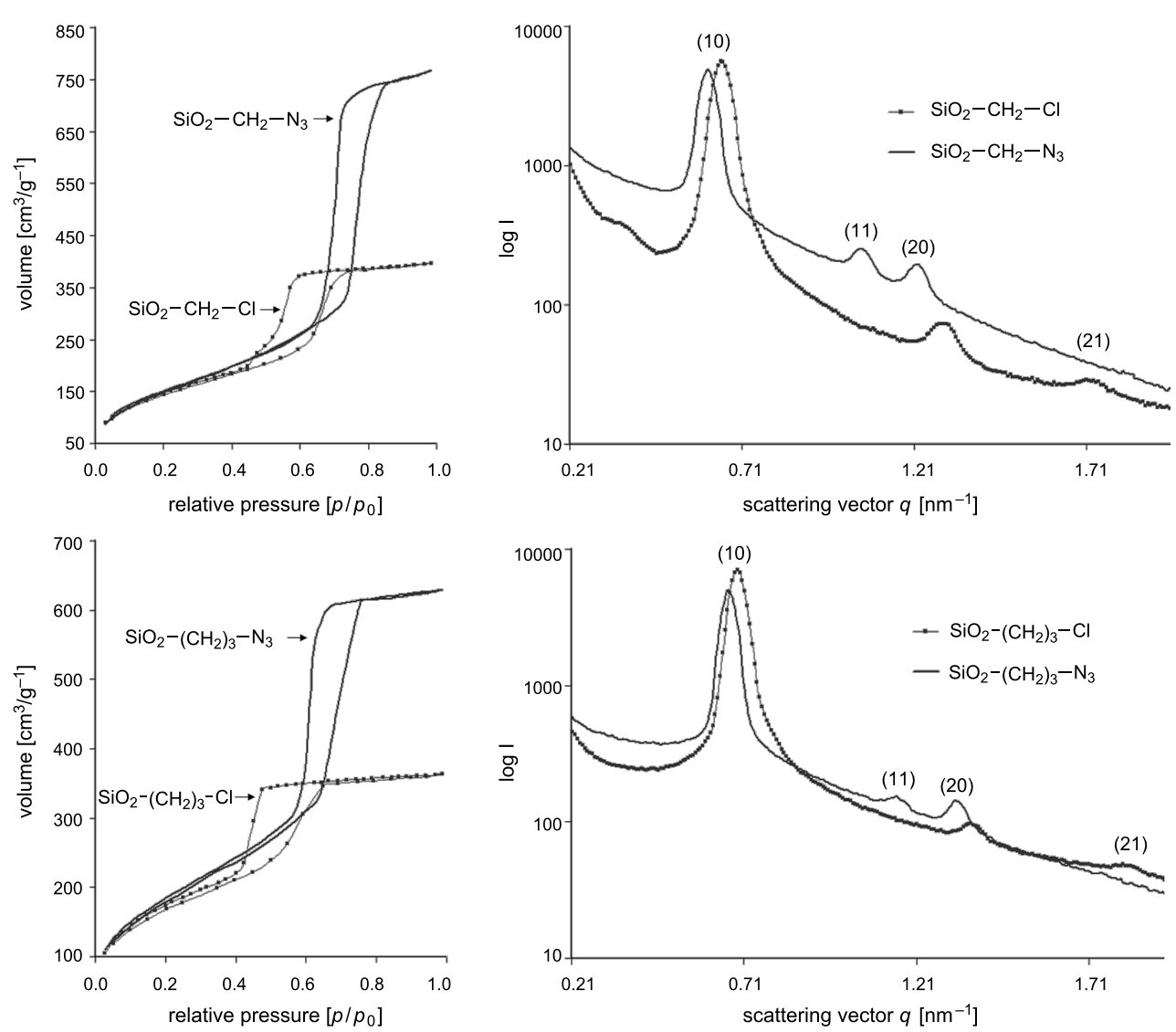

Figure 2: Nitrogen sorption isotherms (taken at $77 \mathrm{~K}$, left) and SAXS patterns (right) of $\mathrm{SiO}_{2}-\left(\mathrm{CH}_{2}\right)_{n}-\mathrm{Cl}_{\text {and }} \mathrm{SiO}_{2}-\left(\mathrm{CH}_{2}\right)_{n}-\mathrm{N}_{3}$ gels after nucleophilic substitution in a saturated DMF/NaN 3 solution at $60{ }^{\circ} \mathrm{C} . n=1$ (top): Prepared from a silica precursor solution containing $4.5 \mathrm{mmol} \mathrm{CMTMS} ; n=3$ (bottom): Prepared from a silica precursor solution containing $3.0 \mathrm{mmol}$ CPES.

Table 1 gives all pore sizes as calculated from the adsorption and desorption isotherms. As expected, the calculation from the adsorption isotherm led to larger pore diameters for all samples with differences in the desorption pore size in the range of 1.7 to $2.4 \mathrm{~nm}$ for the methyl-spacer samples $(n=1)$, and in the range of 1.0 to $1.3 \mathrm{~nm}$ for the propyl-spacer samples $(n=3)$. Regardless of which sorption branch was applied for the calculation, a significant enlargement in the mesopore diameter after nucleophilic substitution in the range of 2.7 to $3.7 \mathrm{~nm}$ for methyl-spacer samples and in the range of 1.5 to $1.9 \mathrm{~nm}$ for propyl-spacer samples was observed. For instance, the chloromethyl-modified sample (3.0 mmol CMTMS) showed a pore diameter $D_{\mathrm{BJH}, \mathrm{Ads}}$ of $5.54 \mathrm{~nm}$ prior to nucleophilic substitution and after conversion into the azides an increase to $D_{\text {BJH,Ads }}=9.17 \mathrm{~nm}$ was detected. The larger amount of nitrogen adsorbed at relative pressures above $p / p_{0}=0.3$ indi-

Table 1: Structural characteristics of $\mathrm{SiO}_{2}-\left(\mathrm{CH}_{2}\right)_{1,3}-\mathrm{Cl}$ compared to corresponding $\mathrm{SiO}_{2}-\left(\mathrm{CH}_{2}\right)_{1,3}-\mathrm{N}_{3}$, obtained from nitrogen sorption analysis at $77 \mathrm{~K}$.

\begin{tabular}{|c|c|c|c|c|c|c|c|c|c|c|}
\hline & \multicolumn{2}{|c|}{$S_{\mathrm{BET}}{ }^{\mathrm{a}}\left[\mathrm{m}^{2} \mathrm{~g}^{-1}\right]$} & \multicolumn{2}{|c|}{$C_{\mathrm{BET}}$} & \multicolumn{2}{|c|}{$V_{\max }\left[\mathrm{cm}^{3} \mathrm{~g}^{-1}\right]$} & \multicolumn{2}{|c|}{$D_{\mathrm{BJH}, \mathrm{Des}}[\mathrm{nm}]^{\mathrm{b}}$} & \multicolumn{2}{|c|}{$D_{\mathrm{BJH}, \mathrm{Ads}}[\mathrm{nm}]^{\mathrm{C}}$} \\
\hline & $\mathrm{SiO}_{2}-\mathrm{Cl}$ & $\mathrm{SiO}_{2}-\mathrm{N}_{3}$ & $\mathrm{SiO}_{2}-\mathrm{Cl}$ & $\mathrm{SiO}_{2}-\mathrm{N}_{3}$ & $\mathrm{SiO}_{2}-\mathrm{Cl}$ & $\mathrm{SiO}_{2}-\mathrm{N}_{3}$ & $\mathrm{SiO}_{2}-\mathrm{Cl}$ & $\mathrm{SiO}_{2}-\mathrm{N}_{3}$ & $\mathrm{SiO}_{2}-\mathrm{Cl}$ & $\mathrm{SiO}_{2}-\mathrm{N}_{3}$ \\
\hline $3.0 \mathrm{mmol}$ CMTMS & 566 & 513 & 80.0 & 56.7 & 347.5 & 650.2 & 3.69 & 6.74 & 5.54 & 9.17 \\
\hline $4.5 \mathrm{mmol}$ CMTMS & 529 & 556 & 64.7 & 66.7 & 397.2 & 768.2 & 4.68 & 7.34 & 6.36 & 9.12 \\
\hline $6.0 \mathrm{mmol}$ CMTMS & 445 & 563 & 56.3 & 55.4 & 325.7 & 768.5 & 3.70 & 7.33 & 5.48 & 9.13 \\
\hline $3.0 \mathrm{mmol}$ CPES & 611 & 664 & 74.8 & 55.7 & 363.0 & 630.0 & 3.50 & 5.37 & 4.82 & 6.34 \\
\hline
\end{tabular}

aCalculated by using the Brunauer-Emmett-Teller (BET) model. ${ }^{b}$ Calculated from the desorption isotherm by using the BJH model. ${ }^{\mathrm{C} C a l c u l a t e d ~ f r o m ~}$ the adsorption isotherm by using the BJH model. 
cates a dramatic increase of the specific pore volumes $\left(V_{\max }\right.$ and $V_{\text {meso }}$ ) after nucleophilic substitution, but relatively constant specific surface areas were observed from the pressure range $\left.p / p_{0}=0.05-0.30\right) . V_{\max }$ and $V_{\text {meso }}$ followed the same trend and showed only slight deviations in their values, thus only $V_{\max }$ is discussed in the course of this work. The difference in $V_{\max }$ between samples before and after nucleophilic substitution was in the range of 300 to $440 \mathrm{~cm}^{3} \mathrm{~g}^{-1}$ for methylspacer samples and in the range of $270 \mathrm{~cm}^{3} \mathrm{~g}^{-1}$ for propylspacer samples (Table 1).

The decreasing $C$-value, indicative of the adsorbent-adsorbate interactions, for gels prepared from a silica-precursor solution containing 3.0-6.0 mmol CMTMS follows the trend expected for gels with increasing coverage of the silica surface with organic groups. For nitrogen sorption on non-modified silica materials, the $C_{\mathrm{BET}}$ values are typically in the range $80-150$ [34].

Figure 2 also shows the SAXS patterns for the modified silica gels before and after nucleophilic substitution of the chlorides into azides $\left(\mathrm{SiO}_{2}-\left(\mathrm{CH}_{2}\right)_{1,3}-\mathrm{Cl} \rightarrow \mathrm{SiO}_{2}-\left(\mathrm{CH}_{2}\right)_{1,3}-\mathrm{N}_{3}\right)$. For all samples, higher order reflections were found, indicating long range ordering of the pore system. $\mathrm{SiO}_{2}-\left(\mathrm{CH}_{2}\right)_{1,3}-\mathrm{N}_{3}$ exhibited the characteristic Bragg reflection sequence for a 2-D hexagonal ordering of $1: 3^{1 / 2}: 2: 7^{1 / 2} \ldots$ and the reflections were indexed to the (10)-, (11)- and (20)-crystallographic planes [35]. A comparison with SAXS patterns of the corresponding $\mathrm{SiO}_{2}-\left(\mathrm{CH}_{2}\right)_{1,3}-\mathrm{Cl}$ precursor material clearly indicates mesostructural changes during the process of nucleophilic substitution. Both, $\mathrm{SiO}_{2}-\left(\mathrm{CH}_{2}\right)_{1,3}-\mathrm{Cl}$ as well as $\mathrm{SiO}_{2}-\left(\mathrm{CH}_{2}\right)_{1,3}-\mathrm{N}_{3}$ showed typical diffraction patterns for a 2-D hexagonal ordering of the pores. However, the relative intensities of the reflections were different for the chloroalkyl-modified silica gels compared to the corresponding azido-modified gels. The intensity of the (11)-reflection was reduced (almost to zero) compared to the corresponding azidoalkyl-modified silica gels. Furthermore, an additional higher order reflection was found for the chloroalkyl-modified precursor material that can be indexed to the (21)-crystallographic plane.

The differences in the reflection intensities before and after nucleophilic substitution (Figure 2) are attributed to the different form factors arising from differences in the respective pore wall thicknesses and pore diameters. One approach to describe these intensities is a two-phase model (pore and silica), where the form factor can be analytically solved (for more details see Supporting Information File 1 and [36]). This model has been previously used to determine the pore diameter and pore-wall thickness of surface functionalized silica gel monoliths [37].

Another approach is based on the reconstruction of the electron densities from a Fourier series and the appropriate choice of the phases $[38,39]$. This has been experimentally and theoretically used to model the electron density across the pore for modified and unmodified MCM-41 and SBA-15 materials [11,40] (for detailed information on SAXS data evaluation, see Supporting Information File 1).

The best solution for the three observed reflections in our case was -+-, which differs to the phase shift from --++ for the first four coefficients for the SBA 15 material observed by Flodström et al. or -++- for the MCM 41 material $[11,40]$. This could be due to the variations in the synthesis conditions of the different materials.

As an example, in Figure 3, the electron density reconstructions are shown for the $\mathrm{SiO}_{2}-\mathrm{CH}_{2}-\mathrm{Cl}$ and $\mathrm{SiO}_{2}-\mathrm{CH}_{2}-\mathrm{N}_{3}$ gels, with $\mathrm{SiO}_{2}-\mathrm{CH}_{2}-\mathrm{Cl}$ exhibiting a smaller pore with a steeper slope of
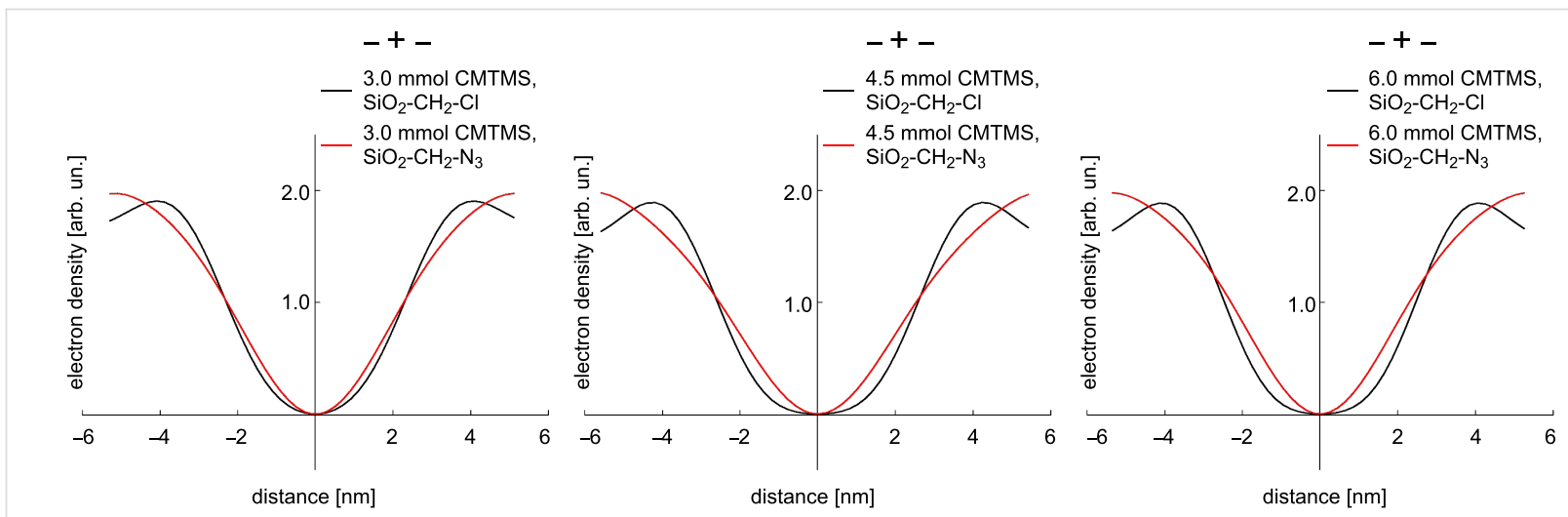

Figure 3: Electron density reconstructions for modified silica gels $\left(\mathrm{SiO}_{2}-\mathrm{CH}_{2}-\mathrm{Cl}\right.$ and $\left.\mathrm{SiO}_{2}-\mathrm{CH}_{2}-\mathrm{N}_{3}\right)$ that have been prepared from a silica precursor solution containing 3.0 (left), 4.5 (middle) and 6.0 (right) mmol CMTMS. The electron density of $\mathrm{SiO}_{2}-\mathrm{CH}_{2}-\mathrm{Cl}$ corresponds to a sharper interface, whereas the broader distribution of $\mathrm{SiO}_{2}-\mathrm{CH}_{2}-\mathrm{N}_{3}$ indicates a higher surface roughness due to the nucleophilic substitution. 
the electron densities, whereas the corresponding substituted gel $\left(\mathrm{SiO}_{2}-\mathrm{CH}_{2}-\mathrm{N}_{3}\right)$ has a broader distribution, which indicates a larger pore with a higher surface roughness.

One would expect the electron density to converge to a constant value within the silica phase. Unfortunately, due to the limited number of peaks available for the reconstruction, the resolution was limited [38,39]. A large constant region would require the sum of a large number of Fourier coefficients, i.e., a large number of diffraction peaks, which are not available for our type of materials. Thus this is an inevitable inherent weakness of the model.

The change in the ratio of the silica wall thickness to the pore diameter, during the nucleophilic substitution process, was also evidenced by nitrogen sorption analysis. An increase in pore diameter was observed (Table 1), while simultaneously a reduction of the pore wall thickness was detected for $\mathrm{SiO}_{2}-\left(\mathrm{CH}_{2}\right)_{1,3}-\mathrm{N}_{3}$ compared to $\mathrm{SiO}_{2}-\left(\mathrm{CH}_{2}\right)_{1,3}-\mathrm{Cl}$ (Table 2).

In the SAXS experiments, this led to the striking appearance of the (11)-reflection and the disappearance of the (21)-reflection. However, whereas sorption analysis indicated a strong decrease of the pore wall thickness, this effect was much less pronounced for the SAXS measurements. One possible explanation could be an additional surface roughness of the pores, which is also in coincidence with the electron density reconstruction (Figure 3). The model description in SAXS (see Supporting Information File 1) as a two-phase material, i.e., cylindrical pores of identical radius embedded in a silica matrix, leads to the measurement of a mean radius and averages out any differences in the radii or effects from surface inhomogeneities or roughness along the length or cross section of the pore. The radius obtained from SAXS could then lie intermediate between the radius obtained in the $\mathrm{BJH}$ analysis, from the adsorption branch and that from the desorption branch, as shown in Figure 4. In the desorption branch, the BJH analysis is restricted, by the

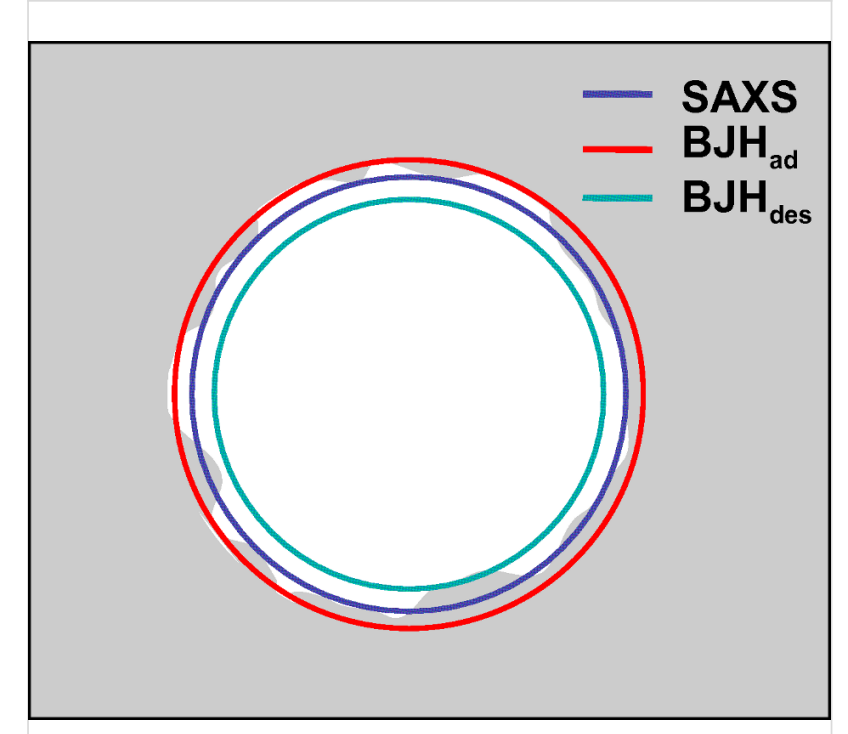

Figure 4: SAXS averages the surface inhomogeneities to a mean radius in the two-phase model and leads therefore to a slightly larger diameter than the nitrogen sorption analysis (desorption branch).

presence of small pores or surface roughness, to give the smallest pore size (Figure 4).

Not only did the reflection intensity change during nucleophilic substitution, but also the relative position of the scattering vector $\mathrm{q}_{(\mathrm{hk})}$ shifted to smaller values (Table 3), indicating an increase of the repeating unit distance. For instance, the chloromethyl-modified sample (4.5 mmol CMTMS) showed a shift of the scattering vector $q_{(10)}$ from 0.65 to $0.61 \mathrm{~nm}^{-1}$ after conversion of the chlorides into the azides, corresponding to an increase of the $d_{(10)}$-spacing from $9.66 \mathrm{~nm}$ to $10.26 \mathrm{~nm}$. The $d_{(10)}$-spacing was used to calculated the lattice constant, which was also found to increase during nucleophilic substitution (Table 3). For example, the chloromethyl-modified sample showed an increase in the lattice constant from $11.15 \mathrm{~nm}$ to $11.85 \mathrm{~nm}$ during nucleophilic substitution.

Table 2: Comparison of the structural characteristics of $\mathrm{SiO}_{2}-\left(\mathrm{CH}_{2}\right)_{1,3}-\mathrm{Cl}$ and the corresponding $\mathrm{SiO}_{2}-\left(\mathrm{CH}_{2}\right)_{1,3}-\mathrm{N}_{3}$.

\begin{tabular}{|c|c|c|c|c|c|c|c|c|}
\hline & \multicolumn{2}{|c|}{$\begin{array}{c}\text { mean pore diameter } \pm 0.3^{a} \\
{[\mathrm{~nm}]}\end{array}$} & \multicolumn{2}{|c|}{$\begin{array}{l}\text { mean wall thickness } \pm 0.3^{a} \\
{[\mathrm{~nm}]}\end{array}$} & \multicolumn{2}{|c|}{$\begin{array}{l}t_{\text {Des }}^{\mathrm{b}} \\
{[\mathrm{nm}]}\end{array}$} & \multicolumn{2}{|c|}{$\begin{array}{l}t_{\text {Ads }}{ }^{c} \\
{[\mathrm{~nm}]}\end{array}$} \\
\hline & $\mathrm{SiO}_{2}-\mathrm{Cl}$ & $\mathrm{SiO}_{2}-\mathrm{N}_{3}$ & $\mathrm{SiO}_{2}-\mathrm{Cl}$ & $\mathrm{SiO}_{2}-\mathrm{N}_{3}$ & $\mathrm{SiO}_{2}-\mathrm{Cl}$ & $\mathrm{SiO}_{2}-\mathrm{N}_{3}$ & $\mathrm{SiO}_{2}-\mathrm{Cl}$ & $\mathrm{SiO}_{2}-\mathrm{N}_{3}$ \\
\hline $3.0 \mathrm{mmol}$ CMTMS & 6.60 & 7.85 & 4.00 & 3.15 & 6.92 & 4.22 & 5.07 & 1.79 \\
\hline $4.5 \mathrm{mmol}$ CMTMS & 7.05 & 8.75 & 4.15 & 3.25 & 6.52 & 4.51 & 4.84 & 2.73 \\
\hline $6.0 \mathrm{mmol}$ CMTMS & 6.65 & 8.10 & 4.05 & 3.15 & 7.02 & 3.87 & 5.24 & 2.07 \\
\hline $3.0 \mathrm{mmol}$ CPES & 6.50 & 7.70 & 4.00 & 3.30 & 7.00 & 5.59 & 5.68 & 4.62 \\
\hline
\end{tabular}

aMean pore diameter and wall thickness calculated from the peak intensities using a two-phase model with an analytical approach. ${ }^{b}$ Wall thickness, calculated by: Lattice constant $a-D_{\mathrm{BJH}, \text { Des }}{ }^{c}$ Wall thickness, calculated by: Lattice parameter $a-D_{\mathrm{BJH}, \text { Ads. }}$ 
Table 3: Structural properties of $\mathrm{SiO}_{2}-\left(\mathrm{CH}_{2}\right)_{1,3}-\mathrm{Cl}$ compared to corresponding $\mathrm{SiO}_{2}-\left(\mathrm{CH}_{2}\right)_{1,3}-\mathrm{N}_{3}$ obtained from SAXS analysis.

\begin{tabular}{|c|c|c|c|c|c|c|}
\hline & \multicolumn{2}{|c|}{$q_{(10)}{ }^{a}\left[\mathrm{~nm}^{-1}\right]$} & \multicolumn{2}{|c|}{$d_{(10)}{ }^{a}[\mathrm{~nm}]$} & \multicolumn{2}{|c|}{$a^{b}[n m]$} \\
\hline & $\mathrm{SiO}_{2}-\mathrm{Cl}$ & $\mathrm{SiO}_{2}-\mathrm{N}_{3}$ & $\mathrm{SiO}_{2}-\mathrm{Cl}$ & $\mathrm{SiO}_{2}-\mathrm{N}_{3}$ & $\mathrm{SiO}_{2}-\mathrm{Cl}$ & $\mathrm{SiO}_{2}-\mathrm{N}_{3}$ \\
\hline $3.0 \mathrm{mmol}$ CMTMS & 0.69 & 0.66 & 9.17 & 9.51 & 10.58 & 10.98 \\
\hline $4.5 \mathrm{mmol}$ CMTMS & 0.65 & 0.61 & 9.66 & 10.26 & 11.15 & 11.85 \\
\hline $6.0 \mathrm{mmol}$ CMTMS & 0.68 & 0.65 & 9.26 & 9.72 & 10.69 & 11.23 \\
\hline $3.0 \mathrm{mmol}$ CPES & 0.69 & 0.67 & 9.10 & 9.45 & 10.50 & 10.91 \\
\hline
\end{tabular}

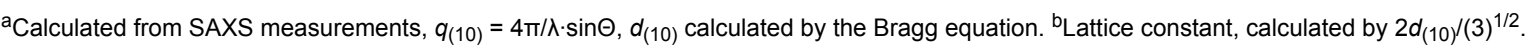

The structural parameters obtained from nitrogen sorption and SAXS analyses suggest a process of mesostructural changes during conversion of $\mathrm{SiO}_{2}-\left(\mathrm{CH}_{2}\right)_{1,3}-\mathrm{Cl}$ into the corresponding $\mathrm{SiO}_{2}-\left(\mathrm{CH}_{2}\right)_{1,3}-\mathrm{N}_{3}$. Figure 5 shows schematically a hexagonally organized porous material with cell parameters $a$, wall thickness $t$, repeating unit distance $d_{10}$ and pore diameter $D$ as obtained from nitrogen sorption.

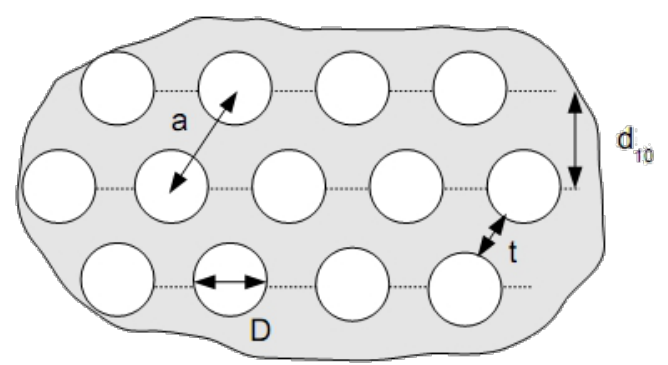

Figure 5: Schematic representation of a hexagonally organized pore system with the characteristic sizes. A similar arrangement is found for the samples by SAXS and transmission electron microscopy (TEM) analyses.

Based on the nitrogen sorption and SAXS analysis, the following trends were observed during nucleophilic substitution: The mesopore diameter and maximal pore volume drastically increased, while the lattice constant showed only a small enlargement with a simultaneous decrease in pore wall thickness. The ratio of pore wall thickness to pore diameter decreased to such an extent, that the new electron density (phase shift of Fourier coefficients) involved a significant change in the reflection intensity. We assume that the reduction in pore wall thickness with a simultaneous increase in pore diameter can not simply be explained by dissolution processes of silica, because the lattice constants also increased during the nucleophilic substitution. Simple ageing of unmodified mesoscopically organized silica gels in azide-containing media allows us to demonstrate that the observed effects are not due to the inserted azide-functionalities, which are covalently attached to the silica surface, but rather to an exposure of a mesostructured silica matrix to azide ions, as presented vide infra.

\section{Ageing of unmodified silica gels in azide- containing media}

From the results obtained above for the chloroalkyl-modified silica gels, the cause of the structural changes cannot be identified clearly and without ambiguity. Therefore, the reaction conditions were changed step by step to isolate the influence of temperature, solvent, anion-cation pair and solvent-azide compositions to identify the critical parameter. Pure (not organically modified) silica gels were kept for $3 \mathrm{~d}$ at $60{ }^{\circ} \mathrm{C}$ (identical conditions as for the nucleophilic substitution described above) in solutions of $\mathrm{NaN}_{3}$ in different solvents ranging from $\mathrm{N}, \mathrm{N}$ dimethylformamide (DMF), 1,1,3,3-tetramethylurea (TMU), 1,3-dimethyl-2-imidazolidinone (DMI) to $\mathrm{H}_{2} \mathrm{O}$. Reference samples were kept for $3 \mathrm{~d}$ at $60{ }^{\circ} \mathrm{C}$ in the respective solvents without azide and pure silica gels were aged at that temperature. In addition, sodium azide was changed to tetramethylammoniumazide $\left(\left(\mathrm{H}_{3} \mathrm{C}\right)_{4} \mathrm{NN}_{3}\right.$, TMAA). All gels were aged, treated with trimethylchlorosilane and dried. The structural characteristics of untreated, reference and silica gels that were exposed to the different reaction conditions were again determined by nitrogen sorption and SAXS analyses. Note that the untreated silica, reference silica and azide-treated silica gels originated from the same monolithic silica piece, which was divided into three parts. Figure 6 shows the nitrogen adsorption/ desorption isotherms taken at $77 \mathrm{~K}$ for gels treated in DMF and DMI; detailed information on gels in $\mathrm{H}_{2} \mathrm{O}$ and TMU is given in Supporting Information File 1.

All isotherms are of type IV with H1 hysteresis loops according to the classification of Sing et al. [33]. The reference samples that were heat treated in the various solvents showed higher pore volumes compared to untreated silica gels, but this effect was clearly intensified by the addition of $\mathrm{NaN}_{3}$, as demonstrated by the stretching of the hysteresis loops along the 

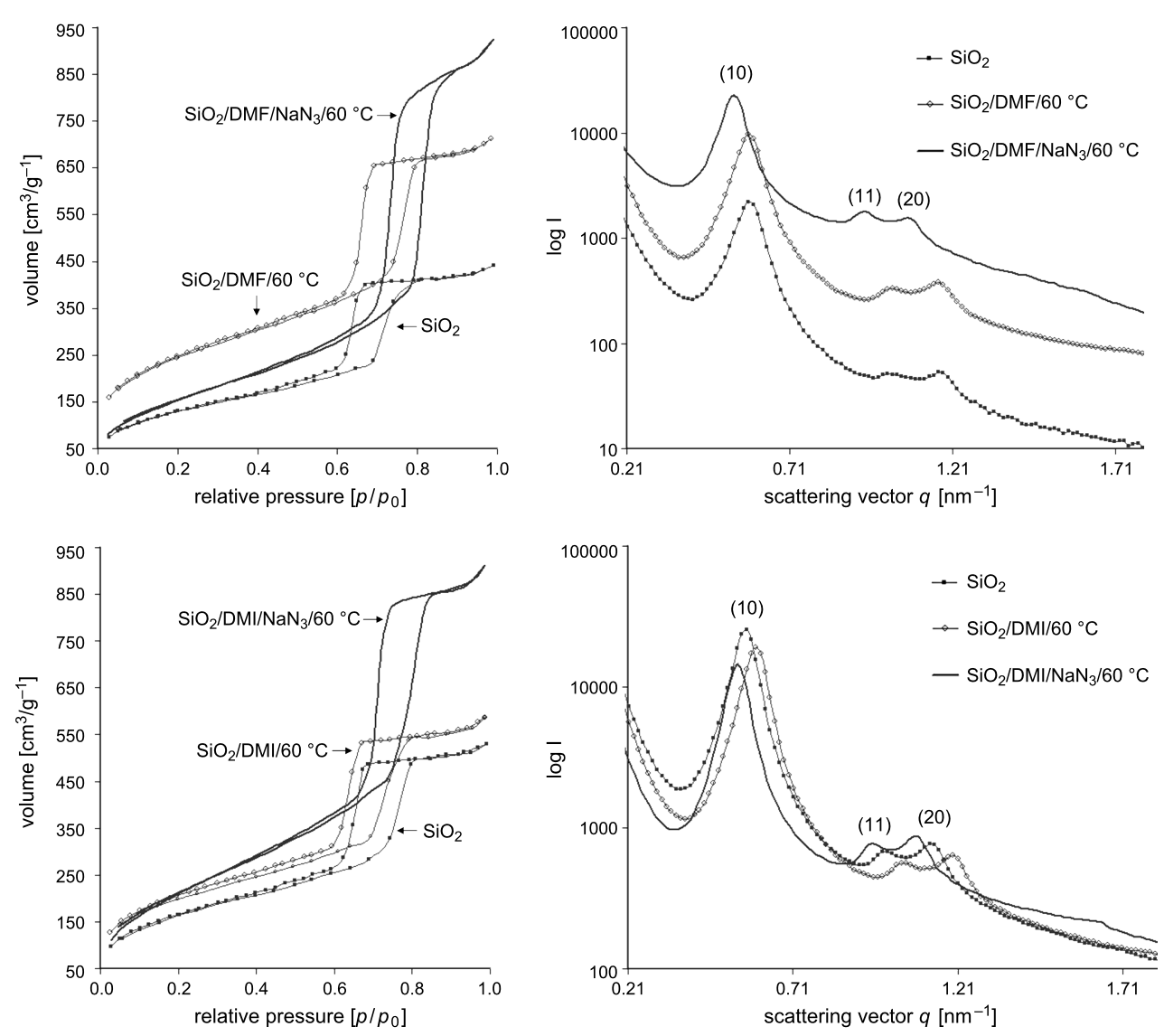

Figure 6: Nitrogen isotherms and SAXS patterns of untreated silica gels, reference silica gels (solvent/60 ${ }^{\circ} \mathrm{C}$ ) and azide-treated silica gels (solvent/ $\mathrm{NaN}_{3} / 60^{\circ} \mathrm{C}$ ) in different solvents: DMF (top) and DMI (bottom).

volume axis. Furthermore, the addition of $\mathrm{NaN}_{3}$ led to a shift of the relative pressure of the pore filling, by capillary condensation, to higher values. Pore diameters were significantly increased by the treatment with azide-containing solvents
(Table 4). Differences in pore diameters for the various samples calculated from the adsorption isotherm in the BJH model were $4.05 \mathrm{~nm}\left(\mathrm{DMF} / \mathrm{NaN}_{3}\right) ; 4.21 \mathrm{~nm}\left(\mathrm{TMU} / \mathrm{NaN}_{3}\right) ; 2.20 \mathrm{~nm}(\mathrm{DMI} /$ $\left.\mathrm{NaN}_{3}\right)$ and $2.25 \mathrm{~nm}\left(\mathrm{H}_{2} \mathrm{O} / \mathrm{NaN}_{3}\right)$. The analogous calculation

Table 4: Structural characteristics of untreated silica, reference silica (solvent/60 ${ }^{\circ} \mathrm{C}$ ) and azide-treated silica gels $\left(\right.$ solvent/ $/ \mathrm{NaN} / 60{ }^{\circ} \mathrm{C}$ ) from nitrogen sorption analysis at $77 \mathrm{~K}$, solvents: DMF and DMI; azide: $\mathrm{NaN}_{3}$ and TMAA.

\begin{tabular}{|c|c|c|c|c|c|}
\hline & $S_{B E T}{ }^{a}\left[\mathrm{~m}^{2} \mathrm{~g}^{-1}\right]$ & $C_{\mathrm{BET}}$ & $V_{\max }\left[\mathrm{cm}^{3} \mathrm{~g}^{-1}\right]$ & $D_{\mathrm{BJH}, \mathrm{Des}}{ }^{\mathrm{b}}[\mathrm{nm}]$ & $D_{\mathrm{BJH}, \mathrm{Ads}}{ }^{\mathrm{c}}[\mathrm{nm}]$ \\
\hline $\mathrm{SiO}_{2}$ & 477 & 62.6 & 441.9 & 5.75 & 7.51 \\
\hline $\mathrm{SiO}_{2} / \mathrm{DMF}$ & 876 & 103.3 & 712.7 & 6.27 & 9.24 \\
\hline $\mathrm{SiO}_{2} / \mathrm{DMF} / \mathrm{NaN}_{3}$ & 592 & 42.2 & 924.8 & 8.01 & 11.56 \\
\hline $\mathrm{SiO}_{2}$ & 607 & 54.1 & 529.6 & 6.21 & 9.35 \\
\hline $\mathrm{SiO}_{2} / \mathrm{DMI}$ & 712 & 110.6 & 586.1 & 5.73 & 7.54 \\
\hline $\mathrm{SiO}_{2} / \mathrm{DMI} / \mathrm{NaN}_{3}$ & 803 & 47.6 & 913.0 & 7.34 & 11.55 \\
\hline $\mathrm{SiO}_{2}$ & 627 & 62.0 & 554.4 & 6.23 & 9.21 \\
\hline $\mathrm{SiO}_{2} / \mathrm{DMF}$ & 906 & 93.0 & 759.4 & 6.74 & 9.18 \\
\hline $\mathrm{SiO}_{2} / \mathrm{DMF} / \mathrm{TMAA}$ & 657 & 50.2 & 856.6 & 7.33 & 11.63 \\
\hline
\end{tabular}

acalculated in the BET model. ${ }^{b}$ Calculated from the desorption isotherm in the BJH model. ${ }^{c}$ Calculated from the adsorption isotherm in the BJH model. 
Table 5: Structural properties as obtained from SAXS analysis of untreated silica, reference silica (solvent/60 ${ }^{\circ} \mathrm{C}$ ) and azide-treated silica gels (solvent/NaN 3 or $\mathrm{TMAA} / 60^{\circ} \mathrm{C}$ ), solvents: $\mathrm{DMF}$ and DMI.

\begin{tabular}{|c|c|c|c|c|c|c|c|}
\hline & $\begin{array}{c}q_{(10)}^{a} \\
{\left[\mathrm{~nm}^{-1}\right]}\end{array}$ & $\begin{array}{l}d_{(10)}{ }^{a} \\
{[\mathrm{~nm}]}\end{array}$ & $\begin{array}{c}a^{b} \\
{[\mathrm{~nm}]}\end{array}$ & $\begin{array}{l}t_{\mathrm{Des}}^{\mathrm{c}} \\
{[\mathrm{nm}]}\end{array}$ & $\begin{array}{l}t_{\text {Ads }}{ }^{\mathrm{d}} \\
{[\mathrm{nm}]}\end{array}$ & $\begin{array}{c}\text { mean pore diameter } \pm 0.2 \\
{[\mathrm{~nm}]}\end{array}$ & $\begin{array}{c}\text { mean wall thickness }{ }^{e} \pm 0.2 \\
{[\mathrm{~nm}]}\end{array}$ \\
\hline $\mathrm{SiO}_{2}$ & 0.59 & 10.73 & 12.39 & 6.68 & 4.92 & 8.60 & 3.80 \\
\hline $\mathrm{SiO}_{2} / \mathrm{DMF}$ & 0.58 & 10.77 & 12.44 & 6.16 & 3.19 & 8.52 & 3.98 \\
\hline $\mathrm{SiO}_{2} / \mathrm{DMF} / \mathrm{NaN}_{3}$ & 0.54 & 11.68 & 13.49 & 5.40 & 1.85 & 10.05 & 3.40 \\
\hline $\mathrm{SiO}_{2}$ & 0.56 & 11.13 & 12.85 & 6.53 & 3.39 & 8.60 & 4.20 \\
\hline $\mathrm{SiO}_{2} / \mathrm{DMI}$ & 0.60 & 10.55 & 12.18 & 6.40 & 4.59 & 8.15 & 4.05 \\
\hline $\mathrm{SiO}_{2} / \mathrm{DMI} / \mathrm{NaN}_{3}$ & 0.54 & 11.60 & 13.39 & 6.07 & 1.86 & 9.20 & 4.20 \\
\hline $\mathrm{SiO}_{2}$ & 0.57 & 11.04 & 12.75 & 6.52 & 3.54 & 8.70 & 4.10 \\
\hline $\mathrm{SiO}_{2} / \mathrm{DMF}$ & 0.61 & 10.27 & 11.86 & 5.12 & 2.68 & 8.15 & 3.85 \\
\hline $\mathrm{SiO}_{2} / \mathrm{DMF} / \mathrm{TMAA}$ & 0.55 & 11.33 & 13.08 & 5.75 & 1.45 & 9.75 & 3.55 \\
\hline
\end{tabular}

${ }^{a}$ Calculated from SAXS measurements, $q_{(10)}=(4 \pi / \lambda) \sin \Theta, d_{(10)}$ calculated by the Bragg equation. ${ }^{b}$ Lattice constant, calculated by $2 d_{(10) /(3)^{1 / 2}}$. ${ }^{\mathrm{W}} \mathrm{all}$ thickness, calculated by: Lattice parameter $a-D_{\mathrm{BJH}, \text { Des. }}{ }^{\mathrm{d}}$ Wall thickness, calculated by: Lattice parameter $a-D_{\mathrm{BJH}, \mathrm{Ads}} .{ }^{\mathrm{e} M e a n}$ pore diameter and wall thickness calculated from the peak intensities (SAXS) using a two-phase model with an analytical approach.

from the desorption branch led to smaller, but still significant, values for the increase in the pore diameter, i.e., $2.26 \mathrm{~nm}(\mathrm{DMF} /$ $\left.\mathrm{NaN}_{3}\right) ; 1.77 \mathrm{~nm}\left(\mathrm{TMU} / \mathrm{NaN}_{3}\right) ; 1.13 \mathrm{~nm}\left(\mathrm{DMI} / \mathrm{NaN}_{3}\right)$ and 1.84 $\mathrm{nm}\left(\mathrm{H}_{2} \mathrm{O} / \mathrm{NaN}_{3}\right)$.

Interestingly, the specific surface area $S_{\mathrm{BET}}$ dramatically increased from $477 \mathrm{~m}^{2} \mathrm{~g}^{-1}$ to $876 \mathrm{~m}^{2} \mathrm{~g}^{-1}$ by treatment of silica gels with pure DMF, whereas by treatment with $\mathrm{DMF} / \mathrm{NaN}_{3}$ the

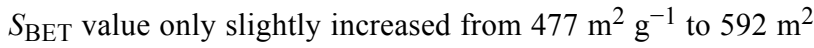
$\mathrm{g}^{-1}$. For the series with DMF this behaviour was reproduced for several samples (Table 4). The sample series with TMU and $\mathrm{H}_{2} \mathrm{O}$ showed the same behaviour, whereas for the series with DMI the sample with additional $\mathrm{NaN}_{3}$ exhibited the highest surface area (Table 4, and Supporting Information File 1).

Higher order reflections were found in the SAXS patterns for every sample, with the characteristic sequence for a 2-D hexagonal ordering of $1: 3^{1 / 2}: 2: 7^{1 / 2} \ldots$ [35]. As noted before for the series with $\mathrm{SiO}_{2}-\left(\mathrm{CH}_{2}\right)_{1,3}-\mathrm{Cl}$ and $\mathrm{SiO}_{2}-\left(\mathrm{CH}_{2}\right)_{1,3}-\mathrm{N}_{3}$, a variation in ratio of the radius of the high electron density region (that is the silica wall) to the inner pore volume was indicated by changes in relative reflection intensities. However, for the unmodified silica gels, neither untreated silica, reference silica nor azide-treated silica displayed the (21)-reflection or disappearance of the (11)-reflection as was seen for $\mathrm{SiO}_{2}-\left(\mathrm{CH}_{2}\right)_{1,3}-\mathrm{Cl}$ or $\mathrm{SiO}_{2}-\left(\mathrm{CH}_{2}\right)_{1,3}-\mathrm{N}_{3}$. This is also reflected in the electron density reconstruction (Figure 2, and Supporting Information File 1). We assume that this is due to differences in the electron density and pore wall thicknesses for unmodified silica compared to silica modified with organic functionalities covalently attached to the silica walls.
After treatment with solvent/ $\mathrm{NaN}_{3}$ at $60{ }^{\circ} \mathrm{C}$ the relative positions of the scattering vectors $q_{(\mathrm{hk})}$ shifted to smaller values (Table 5, and Supporting Information File 1) indicating an increase of the repeating unit distances. This was accompanied by an increase in the lattice constants, with $\mathrm{a}=13.49 \mathrm{~nm}$ for samples that have been treated in DMF with the addition of $\mathrm{NaN}_{3}$, and $\mathrm{a}=13.44 \mathrm{~nm}$ for the respective TMU and $\mathrm{a}=13.39$ $\mathrm{nm}$ for DMI samples. With $\mathrm{H}_{2} \mathrm{O} / \mathrm{NaN}_{3}$ a slightly smaller lattice constant of $13.22 \mathrm{~nm}$ was observed (Supporting Information File 1).

With DMF, TMU and DMI we deliberately chose aprotic solvents that would not solvate the azide ions. This is important when azides are made to react by nucleophilic substitution, since assuming a bimolecular mechanism $\left(\mathrm{S}_{\mathrm{N}} 2\right)$, the rate constant will be increased by a unsolvated, and therefore not stabilized, nucleophilic agent. This is in agreement with the fact that when methanol was used as the solvent for the nucleophilic substitution, the yield was much lower. However, the results from the series of gels treated in $\mathrm{H}_{2} \mathrm{O}$ clearly demonstrate that the effect on the mesostructure is due to the azide ions, independent of the coordination environment of the azide.

Substitution of $\mathrm{NaN}_{3}$ by $\left(\mathrm{H}_{3} \mathrm{C}\right)_{4} \mathrm{NN}_{3}$ (tetramethylammoniumazide, TMAA) led to similar effects on the mesostructure as mentioned above. An unmodified silica gel was kept for $3 \mathrm{~d}$ at $60{ }^{\circ} \mathrm{C}$ in a solution of TMAA in DMF. A reference sample was kept for $3 \mathrm{~d}$ at $60{ }^{\circ} \mathrm{C}$ in DMF. The structural characteristics of untreated silica, reference silica and silica gels that were exposed to DMF/TMAA (all originating from the same gel monolith) were again determined by nitrogen sorption and SAXS analyses. 

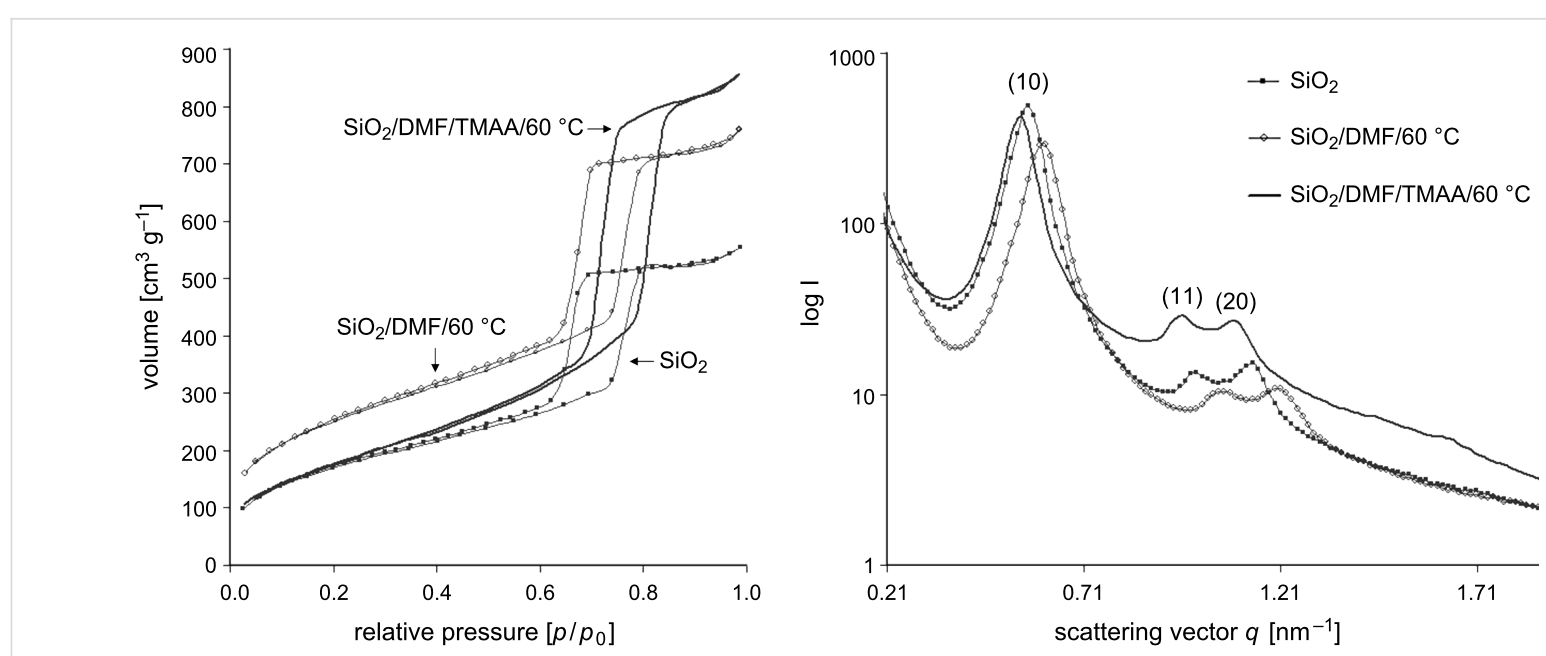

Figure 7: Nitrogen isotherms at $77 \mathrm{~K}$ and SAXS patterns of untreated silica, reference silica (DMF/60 ${ }^{\circ} \mathrm{C}$ ) and azide-treated silica gels (DMF/TMAA $\left.60^{\circ} \mathrm{C}\right)$.

Figure 7 shows the nitrogen sorption isotherms and SAXS patterns. As observed previously for $\mathrm{NaN}_{3}$, the addition of TMAA leads to a shift of the relative pressure of the capillary condensation step to larger values, indicating an increase in mesopore diameter. Calculation from the desorption isotherm in the BJH model indicated an increase in the pore diameter from 6.23 to $7.33 \mathrm{~nm}$, and calculation from the adsorption isotherm indicated an increase from $9.21 \mathrm{~nm}$ to $11.63 \mathrm{~nm}$ (Table 4). The specific surface area $S_{\mathrm{BET}}$ showed the same behaviour as for the series with $\mathrm{DMF} / \mathrm{NaN}_{3}$ (Table 4). By treatment with pure DMF, a dramatic increase from $627 \mathrm{~m}^{2} \mathrm{~g}^{-1}$ to $906 \mathrm{~m}^{2} \mathrm{~g}^{-1}$ was observed, whereas by addition of the azide the $S_{\mathrm{BET}}$ value remained almost constant.

Higher order reflections with the same characteristic sequence for a 2-D hexagonal ordering of $1: 3^{1 / 2}: 2: 7^{1 / 2} \ldots$ were found. As observed for the series before, exposure to the azide compound led to a shift of positions for the scattering vectors $q_{(\mathrm{hk})}$ to smaller values, indicating an increase of the repeating unit distance. In addition to that, an increase in the lattice constant was detected. A value of $13.08 \mathrm{~nm}$ was found for the sample that was treated with DMF and addition of TMAA in comparison to $12.75 \mathrm{~nm}$ for the untreated sample.

Exposure of silica gels to TMAA led to the same mesostructural effects as observed for $\mathrm{NaN}_{3}$. Therefore, substitution of a relatively small counter ion $\left(\mathrm{Na}^{+}\right)$by a sterically demanding counter ion $\left(\left(\mathrm{H}_{3} \mathrm{C}\right)_{4} \mathrm{~N}^{+}\right)$did not change the observed effects of azides on mesoscopically organized silica gels.

\section{Conclusion}

In summary, it was shown that a simple nucleophilic substitution reaction of chloroalkyl-functionalities on a silica surface to azidoalkyl-functionalities had an unexpected and drastic effect on the mesoporous structure. For such co-condensed silica samples with chloroalkyl-functionalities on the surface, an increase in the mesopore diameter, pore volumes ( $V_{\max }$ and $V_{\text {meso }}$ ) and lattice constant with a simultaneous decrease in pore wall thickness was observed upon nucleophilic substitution in $\mathrm{NaN}_{3}$ and DMF. Interestingly no influence on the macroscopic morphology (monoliths) and macroporous network was observed. In principle the same structural changes, albeit less pronounced, were observed for pure silica gels that have been treated in the presence of azide ions.

Further studies have shown that the structural changes can be related to the presence of the azide ions and are not due to the higher processing temperatures, counter ions or solvent molecules, as has been tested for $N, N$-dimethylformamide, 1,1,3,3tetramethylurea, 1,3-dimethyl-2-imidazolidinone and water as the solvent, as well as tetramethylammonium cations as the counter ion.

Therefore, exposure to an azide-containing medium can be seen as a new postsynthetic approach to influence the mesostructural properties of highly porous silica gels.

\section{Experimental}

Materials: Tetraethylorthosilicate (TEOS, Fluka), 3-(chloropropyl)-triethoxysilane (CPES, Aldrich), chloromethyltrimethoxysilane (CMTMS, Wacker Chemie AG), and trimethylchlorosilane (TMCS, Merck) were used without further purification. Ethylene glycol (EG, Aldrich) was purified by drying with $\mathrm{Na}_{2} \mathrm{SO}_{4}$ and distillation from $\mathrm{Mg}$. Pluronic P123 $\left(M_{\mathrm{av}}=5800\right), \mathrm{EO}_{20} \mathrm{PO}_{70} \mathrm{EO}_{20}$ (BASF) was applied without purification. For preparation of saturated azide solutions, 
sodium azide (Merck), tetramethylammoniumchloride (TMAC, Alfa Aesar) and tetramethylammoniumazide (TMAA, synthesized as described below), $N, N$-dimethylformamide (DMF, VWR), 1,3-dimethyl-2-imidazolidinone (DMI, Aldrich) and 1,1,3,3-tetramethylurea (TMU, Aldrich), were used without further purification.

Preparation of hierarchically organized silica gels: Tetrakis(2-hydroxyethyl)orthosilicate (EGMS) was synthesized according to Brandhuber et al. [41,42]. Hierarchically organized silica gels were prepared by condensation of EGMS in an aqueous reaction mixture containing P123 as the structuredirecting agent and hydrochloric acid as the catalyst, according to a percentage by weight ratio of $\mathrm{SiO}_{2} / \mathrm{P} 123 / 1 \mathrm{M} \mathrm{HCl}: 18 / 30 /$ $70 \mathrm{wt} \%$. The reaction mixture was homogenized for $1 \mathrm{~min}$ using a vortex stirrer to obtain a viscous white mixture, which was allowed to gel in a closed PP cylinder at $40^{\circ} \mathrm{C}$. The gels were kept at the same temperature for $7 \mathrm{~d}$ after gelation for ageing. Immersion of the wet gels in a solution of $10 \mathrm{wt} \%$ of trimethylchlorosilane (TMCS) in petroleum ether (PE) for $24 \mathrm{~h}$ and washing with PE and ethanol according to [37] resulted in complete expulsion of Pluronic P123, water and glycol.

Preparation of chloroalkyl-modified silica gels: Chloroalkylmodified silica gels were prepared according to [29] by a co-condensation of EGMS and CMTMS or CPES in various molar ratios of EGMS:CMTMS $=9: 1 ; 6.75: 1$ and 4.5:1. EGMS and CPES were used in a molar ratio of 9:1. The exact compositions can be found in Table 6 . The gels were kept at the same temperature for $7 \mathrm{~d}$ after gelation for ageing. The wet gels were immersed in a solution of $10 \mathrm{wt} \%$ of trimethylchlorosilane (TMCS) in petroleum ether (PE) for $24 \mathrm{~h}$ to react with the free silanol groups, and washed by repeated immersion and storage of the whole monoliths into PE (three times within $24 \mathrm{~h}$ ) and ethanol (five times within $48 \mathrm{~h}$ ).

Nucleophilic substitution: The wet chloroalkyl-modified silica gels were immersed into a saturated solution of $\mathrm{NaN}_{3}$ in DMF at $60{ }^{\circ} \mathrm{C}$, kept for $3 \mathrm{~d}$ and subsequently purified by repeated immersion in water (five times within $24 \mathrm{~h}$ ) and ethanol (three times within $48 \mathrm{~h}$ ) to remove unchanged $\mathrm{NaN}_{3}$. Drying of the wet silica gels was performed by simple evaporation of the solvent under reduced pressure at $60{ }^{\circ} \mathrm{C}$.

Ageing of the silica gels in azide-containing media: Azide solutions of $\mathrm{NaN}_{3}$ in DMF or TMU were prepared by heating under reflux for $8 \mathrm{~h}$ at $80{ }^{\circ} \mathrm{C}$ followed by decantation from residual sediment at room temperature. A solution of $\mathrm{NaN}_{3}$ $(0.1 \mathrm{~g})$ in DMI $(40 \mathrm{~mL})$ was refluxed for $8 \mathrm{~h}$ at $80^{\circ} \mathrm{C}$, resulting in a transparent solution. A solution of $\mathrm{NaN}_{3}(0.1 \mathrm{~g})$ in $\mathrm{H}_{2} \mathrm{O}$ $(40 \mathrm{~mL})$ was prepared at room temperature, resulting in a transparent solution. A solution of TMAA in DMF was prepared by mixing $0.78 \mathrm{~g}$ TMAC $(0.78 \mathrm{~g})$ and $\mathrm{NaN}_{3}(0.46 \mathrm{~g})$ in DMF $\left(70 \mathrm{~mL}\right.$ ) followed by refluxing for $8 \mathrm{~h}$ at $80{ }^{\circ} \mathrm{C}$ and filtration. The wet silica gels were immersed into the azide solutions at $60{ }^{\circ} \mathrm{C}$ and kept for $3 \mathrm{~d}$. Purification and drying of the wet gels was performed as describe above.

Characterization: The azide functionalities were detected by ATR-FT-IR spectroscopy using a Bruker Tensor 27. The density of the azides on the surface was calculated by the specific surface area $\left(S_{\mathrm{BET}}\right)$ and the percentage of nitrogen, which was determined by elemental analysis of nitrogen using an ELEMENTAR Varino, according to:

$$
\rho(\text { azide })=\frac{m_{\mathrm{N}} \cdot N_{\mathrm{A}}}{M_{\mathrm{N}} \cdot 300 \cdot S_{\mathrm{BET}} \cdot 10^{18}}
$$

where $m_{\mathrm{N}}$ is the mass of nitrogen in $100 \mathrm{~g}$ of the silica gel, $N_{\mathrm{A}}$ is Avogadro's constant, $M_{\mathrm{N}}$ is the molar mass of nitrogen and $S_{\mathrm{BET}}$ is the specific surface area according to the Brunauer-Emmett-Teller (BET) model.

Adsorption/desorption isotherms of nitrogen at $77 \mathrm{~K}$ were obtained with a NOVA 4000e (Quantachrome). Prior to analysis the samples were degassed at $60{ }^{\circ} \mathrm{C}$ for $3 \mathrm{~h}$. The specific surface area was evaluated using sorption data in a relative pressure range of $0.05-0.30$ with a five-point-analysis

\begin{tabular}{|c|c|c|c|c|c|c|}
\hline \multicolumn{2}{|c|}{ EGMS } & \multicolumn{3}{|c|}{ chloroalkyltrialkoxysilane } & \multicolumn{2}{|c|}{ template } \\
\hline $\mathrm{SiO}_{2}$ content [\%] ${ }^{\mathrm{a}}$ & amount $[\mathrm{g}]$ & organo-functional silane & amount [mL] & amount [mmol] & $\mathrm{P} 123[\mathrm{~g}]$ & $1 \mathrm{M} \mathrm{HCl}[g]$ \\
\hline 21.8 & 8.20 & - & - & - & 3 & 7 \\
\hline 21.8 & 7.38 & CMTMS & 0.38 & 3.0 & 3 & 7 \\
\hline 21.3 & 7.10 & CMTMS & 0.57 & 4.5 & 3 & 7 \\
\hline 21.3 & 6.82 & CMTMS & 0.78 & 6.0 & 3 & 7 \\
\hline 21.8 & 7.35 & CPES & 0.72 & 3.0 & 3 & 7 \\
\hline
\end{tabular}

aDetermined by TG analysis. 
according to the BET model. Small angle X-ray scattering (SAXS) experiments were performed either with a Bruker Nano-Star or a Bruker Nano-Star (turbospeed solution) and a 2-D position sensitive detector (HiStar or Vantec 2000). Both instruments are equipped with a pinhole generator, where the $\mathrm{X}$-ray beam is collimated and monochromatized by crossed Göbel mirrors.

The pore-to-pore distances of the mesoporous structures were obtained from the first Bragg peak, the $d_{(10)}$ reflection. The lattice constant $a$ was calculated by $2 d_{(10)} /(3)^{1 / 2}$. The pore diameter and the pore wall thickness were calculated from the peak intensities using a two-phase model with an analytical approach $[36,37]$ or alternatively from an electron density reconstruction with the appropriate choice of phases for hexagonal structures [11,37,38].

For comparison, the pore size was obtained from the Barrett-Joyner-Halenda (BJH) model from the de- and adsorption branch of the isotherm and the pore wall thickness derived from the pore-to-pore distance from the SAXS measurements and subtraction of the corresponding pore diameter from the BJH model.

\section{Supporting Information}

Supporting Information features a detailed description on the evaluation of SAXS data, as well as extensive measurement data on unmodified silica gels.

\section{Supporting Information File 1}

Evaluation of the SAXS data and measurements of unmodified gels.

[http://www.beilstein-journals.org/bjnano/content/ supplementary/2190-4286-2-52-S1.pdf]

\section{Acknowledgements}

We acknowledge the financial support of the Deutsche Forschungsgemeinschaft DFG within the collaborative research network SFB 569 and the Austrian Science Fund FWF (DACH project I449). We thank the Wacker Chemie AG for providing chemicals. M. Lindén is gratefully acknowledged for helpful discussions, and we thank D. Mannes for the small angle X-ray scattering measurements, C. Egger for the nitrogen sorption measurements and M. Lang for the elemental analyses.

\section{References}

1. Colombo, P.; Vakifahmetoglu, C.; Costacurta, S. J. Mater. Sci. 2010, 45, 5425-5455. doi:10.1007/s10853-010-4708-9
2. Schüth, F.; Sing, K. S. W.; Weitkamp, J., Eds. Handbook of Porous Solids; Wiley-VCH: Weinheim, Germany, 2002.

3. Ahmed, A.; Clowes, R.; Myers, P.; Zhang, H. J. Mater. Chem. 2011, 21, 5753-5763. doi:10.1039/c0jm02664f

4. Kresge, C. T.; Leonowicz, M. E.; Roth, W. J.; Vartuli, J. C.; Beck, J. S. Nature 1992, 359, 710-712. doi:10.1038/359710a0

5. Beck, J. S.; Vartuli, J. C.; Roth, W. J.; Leonowicz, M. E.; Kresge, C. T.; Schmitt, K. D.; Chu, C. T. W.; Olson, D. H.; Sheppard, E. W.; McCullen, S. B.; Higgins, J. B.; Schlenker, J. L. J. Am. Chem. Soc. 1992, 114, 10834-10843. doi:10.1021/ja00053a020

6. Galarneau, A.; Cambon, H.; Di Renzo, F.; Fajula, F. Langmuir 2001, 17, 8328-8335. doi:10.1021/la0105477

7. Schüth, F. Angew. Chem., Int. Ed. 2003, 42, 3604-3622. doi:10.1002/anie.200300593

8. Alfredsson, V.; Keung, M.; Monnier, A.; Stucky, G.; Unger, K.; Schüth, F. J. Chem. Soc., Chem. Commun. 1994, 921-922. doi:10.1039/C39940000921

9. Zhao, D.; Feng, J.; Huo, Q.; Melosh, N.; Fredrickson, G. H.; Chmelka, B. F.; Stucky, G. D. Science 1998, 279, 548-552. doi:10.1126/science.279.5350.548

10. Zhao, D.; Huo, Q.; Feng, J.; Chmelka, B. F.; Stucky, G. D. J. Am. Chem. Soc. 1998, 120, 6024-6036. doi:10.1021/ja974025i

11. Flodström, K.; Teixrira, C. V.; Amenitsch, H.; Alfredsson, V.; Lindén, M. Langmuir 2004, 20, 4885-4891. doi:10.1021/la049637c

12. Ryoo, R.; Ko, C. H.; Kruk, M.; Antochshuk, V.; Jaroniec, M. J. Phys. Chem. B 2000, 104, 11465-11471. doi:10.1021/jp002597a

13. Yu, C.; Tian, B.; Fan, J.; Stucky, G. D.; Zhao, D. Chem. Commun. 2001, 2726-2727. doi:10.1039/b107640j

14. Sakatani, Y.; Boissiére, C.; Grosso, D.; Nicole, L.; Soler-Illia, G. J. A. A.; Sanchez, C. Chem. Mater. 2008, 20, 1049-1056. doi:10.1021/cm701986b

15. Sel, O.; Kuang, D. B.; Thommes, M.; Smarsly, B. Langmuir 2006, 22, 2311-2322. doi:10.1021/la0520841

16. Nakanishi, K.; Tanaka, N. Acc. Chem. Res. 2007, 40, 863-873. doi:10.1021/ar600034p

17. Smått, J.-H.; Schunk, S.; Lindén, M. Chem. Mater. 2003, 15, 2354-2361. doi:10.1021/cm0213422

18. Hartmann, S.; Brandhuber, D.; Hüsing, N. Acc. Chem. Res. 2007, 40, 885-894. doi:10.1021/ar6000318

19. Chou, K.; Lee, B. I. J. Mater. Sci. 1994, 29, 3565-3571. doi:10.1007/BF00352064

20. He, F.; Zhao, H. L.; Qu, X. H.; Zhang, C. J.; Qiu, W. H. J. Mater. Process. Technol. 2009, 209, 1621-1626. doi:10.1016/j.jmatprotec.2008.04.009

21. Li, Q.; Wu, Z.; Feng, D.; Tu, B.; Zhao, D. J. Phys. Chem. C 2010, 114, 5012-5019. doi:10.1021/jp9100784

22. Galarneau, A.; lapichella, J.; Bonhomme, K.; Di Renzo, F.; Kooyman, P.; Terasaki, O. T.; Fajula, F. Adv. Funct. Mater. 2006, 16, 1657-1667. doi:10.1002/adfm.200500825

23. Galarneau, A.; Cambon, H.; Di Renzo, F.; Ryoo, R.; Choi, M.; Fajula, F. New J. Chem. 2003, 27, 73-79. doi:10.1039/b207378c

24. Bruhwiler, D. Nanoscale 2010, 2, 887-892. doi:10.1039/c0nr00039f

25. Sanchez, C.; Shea, K. J.; Kitagawa, S., Eds. Hybrid materials. Chem. Soc. Rev. 2011, 40, 453-1152. doi:10.1039/c1cs90002a

26. Ortega-Munoz, M.; Lopez-Jaramillo, J.; Hernandez-Mateo, F.; Santoyo-Gonzales, F. Adv. Synth. Catal. 2006, 348, 2410-2420. doi:10.1002/adsc.200600254

27. Guo, Z.; Lei, A.; Liang, X.; Xu, Q. Chem. Commun. 2006, 4512-4514. doi:10.1039/b610733h 
28. Guo, Z.; Lei, A.; Zhang, Y.; Xu, Q.; Xue, X.; Zhang, F.; Liang, X. Chem. Commun. 2007, 2491-2493. doi:10.1039/b701831b

29. Keppeler, M.; Hüsing, N. New J. Chem. 2011, 35, 681-690. doi:10.1039/c0nj00645a

30. Haensch, C.; Hoeppener, S.; Schubert, U. S. Chem. Soc. Rev. 2010, 39, 2323-2334. doi:10.1039/b920491a

31. Sing, K. S. W.; Everett, D. H.; Haul, R. A. W.; Moscou, L.; Pierotti, R. A.; Rouquéol, J.; Siemieniewska, T. Pure Appl. Chem. 1985, 57, 603-619. doi:10.1351/pac198557040603

32. Kleitz, F.; Czuryszkiewicz, T.; Solovyov, L. A.; Lindén, M. Chem. Mater. 2006, 18, 5070-5079. doi:10.1021/cm061534n

33. Gregg, S. J.; Sing, K. S. W. Adsorption, Surface Area and Porosity, 2nd ed.; Academic Press: London, UK, 1982.

34. Rouquerol, F.; Rouquerol, J.; Sing, K. S. W. Adsorption by powders \& porous solids: principles, methodology and applications; Academic Press: San Diego, CA, USA, 1999.

35. Soni, S. S.; Botons, G.; Bellour, M.; Narayanan, T.; Gibaud, A. J. Phys. Chem. B 2006, 110, 15157-15165. doi:10.1021/jp062159p

36. Jähnert, S.; Müter, D.; Prass, J.; Zickler, G. A.; Paris, O.; Findenegg, G. H. J. Phys. Chem. C 2009, 113, 15201-15210. doi:10.1021/jp8100392

37. Brandhuber, D.; Peterlik, H.; Hüsing, N. J. Mater. Chem. 2005, 15, 3896-3902. doi:10.1039/b505976c

38. Turner, D. C.; Gruner, S. M. Biochemistry 1992, 31, 1340-1355. doi:10.1021/bi00120a009

39. Harper, P. E.; Mannock, D. A.; Lewis, R. N. A. H.; McElhaney, R. N.; Gruner, S. M. Biophys. J. 2001, 81, 2693-2706. doi:10.1016/S0006-3495(01)75912-7

40. Beurroies, I.; Agren, P.; Buchel, G.; Rosenholm, J. B.; Amenitsch, H.; Denoyel, R.; Lindén, M. J. Phys. Chem. B 2006, 110, 16254-16260. doi:10.1021/jp053746y

41. Hüsing, N.; Brandhuber, D.; Torma, V.; Raab, C.; Peterlik, H.; Kulak, A. Chem. Mater. 2005, 17, 4262-4271. doi:10.1021/cm048483j

42. Hüsing, N.; Raab, C.; Torma, V.; Brandhuber, D.; Peterlik, H. J. Mater. Chem. 2005, 15, 1801-1806. doi:10.1039/b417675h

\section{License and Terms}

This is an Open Access article under the terms of the Creative Commons Attribution License (http://creativecommons.org/licenses/by/2.0), which permits unrestricted use, distribution, and reproduction in any medium, provided the original work is properly cited.

The license is subject to the Beilstein Journal of Nanotechnology terms and conditions: (http://www.beilstein-journals.org/bjnano)

The definitive version of this article is the electronic one which can be found at: $\underline{\text { doi: } 10.3762 / \text { bjnano. } 2.52}$ 